\title{
Metropolização brasileira: um estudo sobre a dinâmica e os indicadores socioespaciais das Regiões Metropolitanas de São Luís e Belém
}

\section{Brazilian metropolization: a study on the dynamics and the socio-spatial indicators of the Metropolitan Regions of São Luís and Belém}

Magno Vasconcelos Pereira Junior - Doutor em Geografia, Planificação Territorial e Gestão Ambiental pela Universidade de Barcelona (UB). Professor Visitante da Universidade Estadual do Maranhão (UEMA).E-mail: magnojr5@hotmail.com

Saint-Clair Cordeiro da Trindade Júnior - Doutor em Geografia Humana pela Universidade de São Paulo (USP). Professor Titular do Núcleo de Altos Estudos Amazônicos (NAEA) da Universidade Federal do Pará (UFPA).E-mail: stclair@ufpa.br

\section{Resumo \\ Este artigo tem como principal objetivo apresentar e analisar o perfil metropolitano de Belém e São Luís através do Índice de Desenvolvimento Humano Municipal (IDHM), do Índice de Vulnerabilidade Social (IVS), da renda per capita e do Produto Interno Bruto (PIB). A pesquisa foi elaborada com base em levantamento e análise bibliográfica sobre o tema, estabelecendo diálogo com autores internacionais e nacionais que trabalham diretamente com a teoria da produção social do espaço, bem como em sistematização de dados secundários e informações documentais levantados em instituições oficiais e que permitiram estabelecer a caracterização socioespacial das duas realidades analisadas. Como resultados, são discutidos elementos da formação das duas regiões metropolitanas, mostrando-se, por meio dos referidos indicadores, as disparidades socioespaciais existentes entre os municípios pertencentes a cada uma delas, assim como são feitas reflexões comparativas entre as duas metrópoles estudadas.}

\section{Palavras-chave}

Metropolização. Desigualdades socioespaciais. Indicadores socioeconômicos. Belém (PA). São Luís (MA).

\begin{abstract}
The primary aim of this article is to present and analyze the metropolitan profile of Belém and São Luís through the Municipal Human Development Index (MHDI), the Social Vulnerability Index (SVI), the per capita income and the Gross Domestic Product (GDP). The research carried out is based on a bibliographic survey and analysis on the theme, establishing a dialogue with international and national authors associated with the theory of the social production of space, as well as on the systematization of secondary data and documentary information collected in official institutions, which allowed to establish the socio-spatial characterization of the two realities in focus. As a result, the article discusses elements of the formation of the two metropolitan regions, showing, through the mentioned indicators, the socio-spatial disparities between their respective municipalities, and makes comparative reflections on both of the metropolises studied.
\end{abstract}

\section{Keywords}

Metropolization. Socio-spatial inequalities. Socioeconomic indicators. Belém (PA). São Luís (MA). 


\section{INTRODUÇÃO}

$\mathrm{Na}$ atualidade, as urbes concentram contingentes populacionais cada vez maiores e, de acordo com previsões da ONU News (ONU PREVÊ..., 2019), para 2050 mais de um terço da população mundial viverá em áreas urbanas ou urbanizadas; fenômeno esse que coincide com as políticas de centralização adotadas por muitos países responsáveis por delegar, assim, um aumento das responsabilidades para os governos locais.

Tal crescimento urbano se acirrou a partir da segunda metade do século XX, quando a sociedade experimentou uma aceleração do processo de metropolização do território, resultado da nova dinâmica econômica global apoiada pelos modernos sistemas tecnológicos em um cenário marcado pelas políticas neoliberais.

O fenômeno está relacionado a momentos de espacialização do capital, e que hoje ganha novos elementos, pautados em novos sistemas tecnológicos e nas novas formas de mobilidade e de comunicação. Diante disso, interessa-nos saber como ocorrem as espacialidades em realidades metropolitanas situadas fora do centro econômico mundial, especialmente no contexto de transformação por que passam regiões como a Amazônia, na qual importantes áreas metropolitanas podem ser reconhecidas, tais como a de Belém, no estado do Pará, e a de São Luís, no estado do Maranhão, ambas situadas na porção centro-oriental daquela região.

Nesse sentido, o objetivo central deste artigo é analisar a dinâmica socioespacial das regiões metropolitanas de Belém (PA) e São Luís (MA) em seus contextos de urbanização e vulnerabilidade, a partir de levantamento de dados secundários do Índice de Desenvolvimento Humano Municipal (IDHM) e do Índice de Vulnerabilidade Social (IVS), e de elementos que ajudam a medir o grau de concentração de renda, como a renda per capita e o Produto Interno Bruto (PIB).

O estudo foi feito com base em levantamento e análise bibliográfica sobre o tema, mobilizando autores que trabalham com a teoria da produção social do espaço. Também foram sistematizados dados secundários e informações documentais levantados em instituições oficiais ${ }^{1}$. Com isso, foi possível estabelecer o perfil e a caracterização socioespacial dos municípios integrantes das duas regiões metropolitanas eleitas para estudo.

Instituto Brasileiro de Geografia e Estatística (IBGE), Instituto Maranhense de Estudos Socioeconômicos e Cartográficos (IMESC), Fundação Amazônia de Amparo a Estudos e Pesquisas (FAPESPA), Instituto de Desenvolvimento Econômico, Social e Ambiental do Pará (IDESP) e Agência Executiva Metropolitana (AGEM) de São Luís. 
Além da presente introdução, o artigo está dividido em duas seções, seguidas das considerações finais. Na primeira seção, são apresentados alguns elementos teórico-conceituais importantes para pensar a metropolização contemporânea. Na segunda, é analisada a formação e a estrutura e o perfil socioespacial das Regiões Metropolitanas de São Luís e de Belém. Por fim, seguem-se as considerações finais a respeito dos principais resultados obtidos.

\section{ELEMENTOS TEÓRICO-CONCEITUAIS PARA PENSAR A METROPOLIZAÇÃO CONTEMPORÂNEA}

A expansão do tecido urbano e a implosão-explosão da cidade já haviam sido notados por Lefebvre (2011) ao apontar aspectos do processo industrial e o desaparecimento gradual do rural com a expansão do fenômeno urbano, como aconteceu na América do Sul:

nessas regiões e países, as antigas estruturas agrárias se dissolvem; camponeses sem posses ou arruinados afluem para a cidades a fim de nelas encontrar trabalho e subsistência. Ora, esses camponeses vêm de explorações destinadas a desaparecer pelo jogo dos preços mundiais, o qual depende estreitamente dos países e dos polos de crescimento industrial. Atualmente, portanto, aprofunda-se um processo induzido que se pode chamar de a "implosão-explosão" da cidade. Fenômeno urbano se estende sobre uma grande parte do território, nos grandes países industriais (LEFEBVRE, 2011, p. 17-18).

A relação cidade e campo foi estudada também por Kayser (1969) por meio da ideia da metropolização do espaço, mostrando a distinção entre os espaços metropolizados e espaços não metropolizados. Aqueles se assentam sobretudo em grandes fluxos de pessoas, mercadorias e capitais; e estes últimos em elementos do rural de caráter mais agrícola, por núcleos não modernos que desempenham com dificuldade o papel de centros de serviços e por densidades demográficas particularmente fracas (KAYSER, 1969, p. 374).

O espaço metropolizado relaciona-se ao modo de distribuição e reorganização do capital e sua capacidade de concentração e de centralidade ${ }^{2}$ das atividades produtivas no espaço. Após a segunda revolução industrial, uma nova ordem do capital se instala e, no final do século XX, manifesta-se a desintegração do território à escala nacional e local, vinculado aos novos padrões mercantilistas da globalização, ou seja, são identificados intensos movimentos de reordenamento responsáveis por novas centralidades.

2 À maneira de Lencioni (2017), entende-se aqui a concentração e a centralidade como processos que estão relacionados, respectivamente, à expansão dos meios de produção e à associação, fusão e reagrupamento de frações individuais de capital. 
Esse processo define uma nova forma da metropolização contemporânea, que estabelece uma estrutura mais descentralizada sustentada pela expansão geográfica do capital. Assim, "longe de apenas reforçar aglomerações singulares, a metropolização passa a engendrar novas morfologias urbanas, muito mais articuladas e densas, ao mesmo tempo que descontínuas, dispersas, sem limites precisos" (MOURA, 2012, p. 6).

Soja (1996) também defende a tese da descentralização na nova dinâmica territorial contemporânea. Evidencia que a metropolização atual não é necessariamente monocêntrica, posto que o processo se torna mais dinâmico e sua influência tende a extrapolar os limites convencionais, conforme se constata em padrões dos movimentos pendulares para trabalho e estudo, pela mobilidade e conectividade, pela dinâmica econômica e pela diversidade funcional:

as dinâmicas do desenvolvimento metropolitano já não são, hoje, tão decididamente monocêntricas, tão determinadas por um modelo singularmente polarizado de forças centrifugas e centrípetas, por um padrão de crescimento urbano que gira em torno definitivo da cidade. A nova metrópole é crescentemente "descentralizada" e cada vez mais um mosaico de desenvolvimento geográfico desigual (SOJA, 1996, p. 154).

Assim, as metrópoles monocentrais tendem a ceder espaço às polinucleadas, de configuração territorial mais dispersa. Para se compreender tais processos de metropolização contemporâneos é necessário considerar a noção de espaço urbano à maneira de Capel (1975):

recientemente el criterio de la cultura urbana y el de la heterogeneidad social y profesional se ha comenzado a considerar insuficiente por algunos autores que entienden que no es ésta realmente la característica esencial de las áreas urbanas y que por sí solo no basta para el desarrollo de los rasgos ciudadanos. Lo que cuenta es, sobre todo, la intensidad de las interrelaciones que se anudan en el interior del espacio urbano (CAPEL, 1975, não paginado).

Tais inter-relações que ocorrem no interior dos espaços urbanos estão hoje intensamente comprometidas com os componentes urbanos do espaço regional do qual fazem parte. Trata-se, por exemplo, da grande intensidade de fluxos de pessoas, mercadorias e capitais, do crescimento das atividades de serviços e da crescente demanda por trabalho imaterial, da concentração de atividades de gestão e administração, da construção de um modo de viver e de consumo que se espelha no perfil da metrópole (LENCIONI, 2013).

Assim, o processo de metropolização contemporâneo já não se caracteriza somente pelos arranjos espaciais em contínua expansão, como no passado, 
frequentemente associados ao fenômeno de conurbação. Adota-se aqui um conceito mais próximo da ideia de cidade-região, uma realidade da espacialidade atual decorrente das formas e intensidades de divisão social e espacial do trabalho que extrapola os limites territoriais convencionais e se mescla a um espaço articulado globalmente por arranjos diversos de interações e de governança (MOURA, 2012; SCOTT; AGNEW; SOJA; STPORPER, 2001), ou seja, estendese também à dimensão econômica, política e territorial:

morfologicamente, esses arranjos absorvem em uma unidade espacial, contínua ou descontínua, centros urbanos e suas áreas intersticiais urbanas e rurais, estreitando relações e dividindo funções com aglomerações vizinhas, alcançando uma escala urbana mais complexa e uma abrangência regional (MOURA, 2012, p. 12).

Nesse novo processo de metropolização nem sempre predomina a homogeneização, pois há evidentes descontinuidades, tanto no tocante aos investimentos de capital, quanto às condições gerais de produção. Isso induz à existência de contrastes sociais e econômicos que produzem estruturas e dinâmicas socioespaciais intraurbanas marcadas por desigualdades exacerbadas, conforme ocorre no Brasil.

\section{FORMAÇÃO E ESTRUTURA SOCIOESPACIAL DAS REGIÕES METROPOLITANAS DE SÃO LUÍS E BELÉM}

O crescimento urbano não ocorreu igualmente em todo o território nacional. Em algumas regiões o processo foi mais intensivo que em outras. $\mathrm{Na}$ década de 1980, por exemplo, as regiões Norte e Nordeste tiveram as menores taxas de urbanização, diferentemente da região Sudeste, que se apresentava como a mais urbanizada (SANTOS, 2008).

Essa disparidade é fruto das políticas de desenvolvimento no território brasileiro. O Centro-Sul passou a ser a porção do País mais modernizada em termos tecnológicos, de infraestruturas, de transportes, de comunicações e de mercado, ao passo que a tardia tecnificação territorial do Norte e Nordeste criou diferentes ritmos de urbanização no País.

Somam-se à intensificação desproporcional da urbanização no País, as heranças dos períodos passados, que desempenham papel ativo no novo processo de urbanização. Nesse sentido, nem todos os espaços regionais foram receptivos a esse novo fenômeno urbano. O desenvolvimento desigual provocou alterações socioespaciais significativas que acarretaram diferenciações geográficas, produzindo discrepâncias socioespaciais e econômicas em diversas escalas. Tais fatores se aplicam aos processos de metropolização de Belém e de São Luís. 
Embora os fatores geográficos e históricos ${ }^{3}$ sejam essenciais para o desenvolvimento local e regional, fatores de ordem política e econômica reforçam o desenvolvimento desigual, disperso e segregado nas mais variadas escalas, pois reproduz, através da acumulação do capital, de suas estratégias e agentes, os interesses do lucro e da mais-valia.

É nesse cenário que se formam, em temporalidades distintas, as Regiões Metropolitanas de Belém (RMB) e da Grande São Luís (RMGSL) ${ }^{4}$. A gênese da primeira remonta ao momento em que a Amazônia se integrava economicamente ao Nordeste e ao Centro-Sul do País, por intermédio de rodovias. Tal processo fez-se acompanhar de profundas contradições muito presentes na formação metropolitana de Belém, das quais decorreram, "de um lado, a consolidação de um modo de vida extremamente moderno, sofisticado e artificializado; e, de outro, o crescimento do baixo terciário, do déficit habitacional, da favelização acentuada, da insuficiência de serviços e de equipamentos urbanos" (TRINDADE JÚNIOR, 1998, p. 94).

Por sua vez, a formação metropolitana de São Luís acompanhou a crescente mudança na estrutura econômica da capital maranhense, com as repercussões da implementação do Programa Grande Carajás e a instalação da Alumar e da Vale S.A., empreendimentos que acarretaram incremento populacional induzido pelas migrações oriundas do interior do estado.

Por conseguinte, foi a dinâmica do capital, acompanhada do ritmo da produção econômica e da modernização urbana, que levaram à formação metropolitana dessas duas realidades urbanas, com características relativamente similares. Tendo isso em vista, realiza-se a seguir uma discussão sobre a gênese e a estrutura atual da RMGSL e da RMB.

\subsection{METROPOLIZAÇÃO DA GRANDE SÃO LUÍS}

Considera-se importante notar que a urbanização da população no estado do Maranhão é um processo relativamente recente. A população maranhense somente passou a ser predominantemente urbana entre os anos de 1997 e 2000 (Figura 1), quase 30 anos após essa tendência ter começado a despontar em nível

\footnotetext{
3 Harvey (2004) reforça a ideia de que a configuração territorial está estreitamente ligada aos processos sociais, mercadológicos e políticos. Esses dois últimos têm um maior peso em relação ao próprio processo histórico, como explica: "as diferenças geográficas são bem mais do que legados histórico-geográficos. Elas estão sendo perpetuamente reproduzidas, sustentadas, solapadas e reconfiguram por meio de processos político-econômicos e sócio-ecológicos que ocorrem no momento presente" (HARVEY, 2004, p. 111).

4 Destaca-se que a denominação "Região Metropolitana da Grande São Luís" possui certa redundância, uma vez que Grande São Luís por si só já caracteriza uma área metropolitana, demonstrando alguns equívocos que permeiam a institucionalização dessas áreas.
} 
nacional. No entanto, essa diferenciação, em comparação com a média do País, trouxe problemas territoriais para as cidades do Maranhão, com destaque para a sua capital, que passou por um intenso processo de transformação.

Figura 1 - Maranhão: população urbana e rural

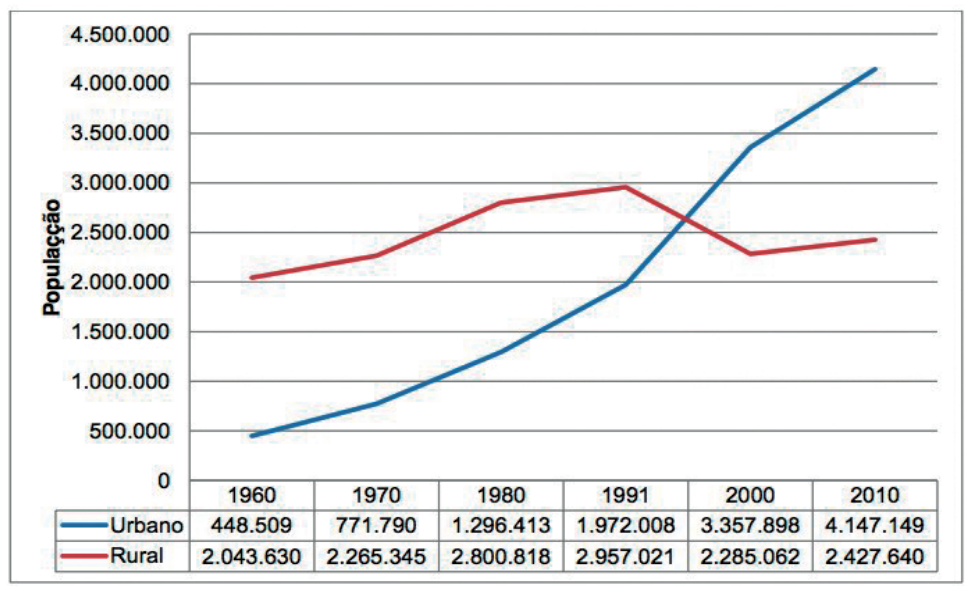

Fonte: Vasconcelos P. Jr. (2015, p. 176).

O incremento populacional na capital do estado se iniciou na década de 1980 como um resultado das políticas territoriais ligadas ao Programa Grande Carajás, as quais tiveram uma grande repercussão no Maranhão ao colocar a cidade de São Luís na rota do capital produtivo, com intensa atração de mão de obra e considerável ampliação da urbanização periférica. A população migrante se instalou em áreas nas quais a infraestrutura urbana era precária:

[...] em regiões isoladas e sem nenhum controle administrativo quanto ao tecido urbano resultante da adição dos vários loteamentos, das relações entre eles e os equipamentos coletivos, da disponibilidade de saneamento básico ou das condições das áreas institucionais exigidas pela legislação, resultando na sequência de cidades dormitórios, sem nenhuma qualidade de um bairro digno deste nome (BURNETT, 2006, p. 13).

Ademais, o deslocamento populacional do interior para a cidade foi agravado por empreendimentos econômicos que não conseguiam absorver a força de trabalho que chegava:

esses projetos com um discurso desenvolvimentista provocaram também um deslocamento de um grande contingente populacional do interior do estado, de estados vizinhos e outras regiões para a capital maranhense, induzindo, desse modo, uma ampliação do setor de serviço. Os complexos industriais que se instalam no Maranhão, apesar do seu grande investimento, não disponibilizam na mesma medida o número de empregos diretos no estado e na sua capital São Luís (MOREIRA, 2013, p. 40). 
Desdobramento importante foi o surgimento de ocupações geradas pelo déficit habitacional, contribuindo para a expansão de palafitas e favelas que passaram a abrigar pessoas vivendo em condições precárias. O incremento populacional acentuou consideravelmente os problemas que já existiam na cidade, como o desemprego e a informalidade do trabalho:

a situação logo se agravava com a permanência do desemprego e a falta de qualificação profissional suficiente para o ingresso no mercado de trabalho, restando, na maioria das vezes, a opção por atuar no setor informal do terciário ou na construção civil. Assim, todos esses eventos proporcionaram à cidade várias mudanças, sendo uma delas o aumento do contingente populacional (PORTELA, 2011, p. 227).

A população, em crescimento acelerado, fixou-se em áreas limítrofes da capital e municípios vizinhos. A desterritorialização e a reterritorialização populacionais ocasionaram processos socioespaciais diversos, induzindo a formação de uma aglomeração metropolitana, como a da Grande São Luís (Mapa 1).

Mapa 1 - Região Metropolitana da Grande São Luís

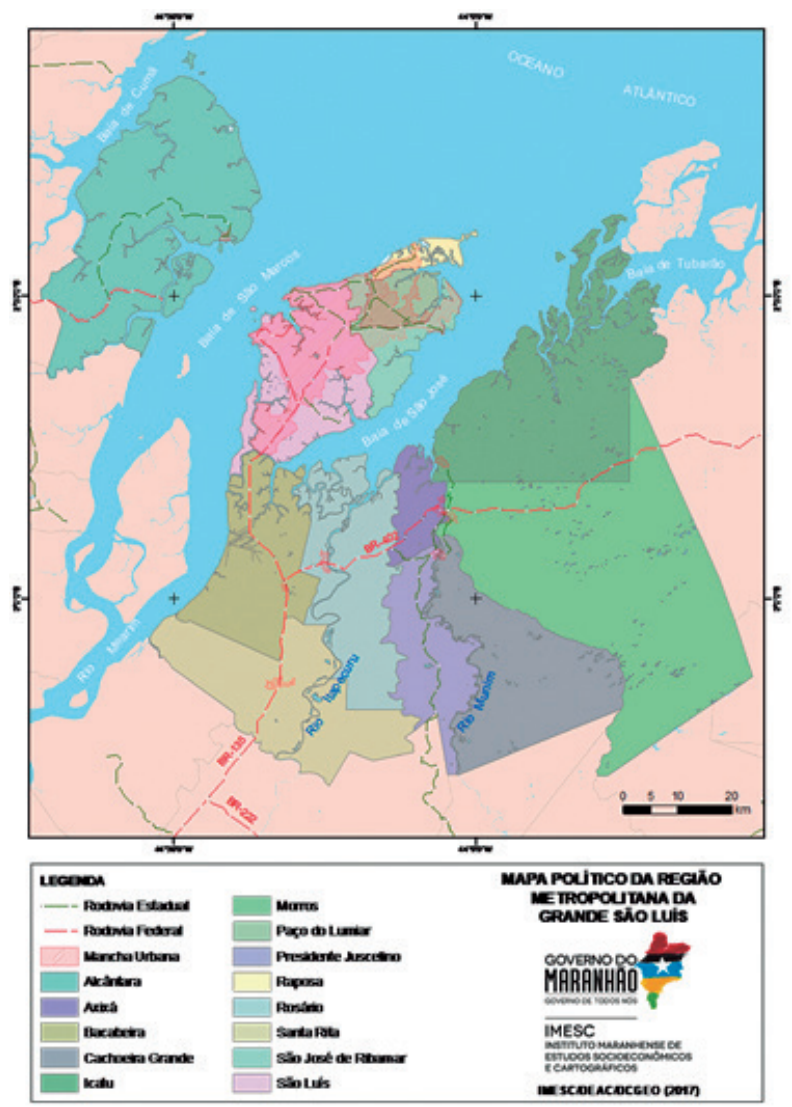

Fonte: IMESC (2017, não paginado). 
É nesse sentido que a institucionalização da RMGSL ocorreu a partir da configuração de aglomerações urbanas cujas atividades socioeconômicas e cuja ocupação do solo urbano ultrapassaram os limites da capital maranhense, e sob o discurso de diminuir as diferenças socioespaciais presentes nos territórios, tornando-se necessária a constituição de políticas regionais que contemplem funções públicas de interesse comum.

A RMGSL foi institucionalizada em 12 de janeiro de 1998 pela Lei Complementar (LC) Estadual no 38 (MARANHÃO, 1998), abrangendo a área territorial de cinco municípios: São Luís, São José de Ribamar, Paço do Lumiar, Raposa e Alcântara. Posteriormente, houve algumas leis complementares que alteraram a sua abrangência territorial. A última alteração foi realizada pela Lei Complementar (LC) Estadual no 174, de 25 de maio de 2015 (MARANHÃO, 2015), que define 13 municípios como integrantes da referida região metropolitana, a saber: São Luís, São José de Ribamar, Raposa, Paço do Lumiar, Alcântara, Bacabeira, Rosário, Axixá, Santa Rita, Presidente Juscelino, Cachoeira Grande, Morros e Icatu (Quadro 1).

Quadro 1 - RMGSL: municípios integrantes

\begin{tabular}{|l|l|}
\hline Lei Complementar & \multicolumn{1}{c|}{ Municípios } \\
\hline$N^{o} 038 / 1998$ & São Luís, São José de Ribamar, Paço do Lumiar e Raposa \\
\hline$N^{o} 069 / 2003$ & $\begin{array}{l}\text { São Luís, São José de Ribamar, Paço do Lumiar, Raposa e } \\
\text { Alcântara }\end{array}$ \\
\hline N $^{\text {o } 153 / 2013}$ & $\begin{array}{l}\text { São Luís, São José de Ribamar, Paço do Lumiar, Raposa, } \\
\text { Alcântara, Rosário, Bacabeira e Santa Rita }\end{array}$ \\
\hline$N^{o} 161 / 2013$ & $\begin{array}{l}\text { São Luís, São José de Ribamar, Paço do Lumiar, Raposa, } \\
\text { Alcântara, Rosário, Bacabeira, Santa Rita e Icatu }\end{array}$ \\
\hline$N^{o} 174 / 2015$ & $\begin{array}{l}\text { São Luís, São José de Ribamar, Paço do Lumiar, Raposa, } \\
\text { Alcântara, Rosário, Bacabeira, Santa Rita, Icatu,Axixá, } \\
\text { Cachoeira Grande, Morros e Presidente Juscelino }\end{array}$ \\
\hline
\end{tabular}

Elaborado por Magno Vasconcelos Pereira Junior com base em Maranhão (1998, 2003, 2013, 2015).

As áreas banhadas pelo rio Munim e que integram a RMGSL, como Axixá, Icatu, Morros, Presidente Juscelino e Cachoeira Grande, apresentam certa dificuldade de compor uma lógica metropolitana mais coesa, em função do distanciamento em relação à capital, da falta de uma estrutura urbana solidificada e de serviços essenciais para a reprodução do capital, da baixa intensidade dos fluxos de informação e comunicação, da deficiência da rede de transporte doméstico de passageiros e cargas entre municípios, das poucas opções de lazer e entretenimento, da incipiente produção e inovação etc. 
Por seu turno, os espaços da RMGSL situados à margem do rio Itapecuru, como Bacabeira, Rosário e Santa Rita, conseguem, de certa forma, apresentar relativa conectividade com a Ilha de São Luís em termos de serviços e mercadorias e que é composta por São Luís, Paço do Lumiar, São José de Ribamar e Raposa. A Ilha é a porção territorial que melhor expressa as formas e os conteúdos metropolitanos, por concentrar a infraestrutura, as atividades e as riquezas.

Situada no chamado Golfão Maranhense, a RMGSL tem uma área de $2.898,93 \mathrm{Km}^{2}$, detêm quase $40 \%$ do PIB do Maranhão e sua população é composta por 1.526.213 habitantes, cerca de $23 \%$ da população total do estado (IBGE, 2016). Dos $1.370 \mathrm{~km}^{2}$ de extensão da Ilha de São Luís, 60\% - o que corresponde a cerca de $827,1 \mathrm{~km}^{2}$ - são ocupados pela capital, cuja população é de 1.108.975 habitantes (IBGE, 2020).

A Lei Complementar no 174 de 2015 (MARANHÃO, 2015), além de incorporar 4 novos municípios na RMGSL, definiu diretrizes que tratam das funções públicas de interesse comum: da gestão e organização da estrutura política e administrativa; do sistema de planejamento metropolitano; do sistema de informações metropolitanas; e das disposições finais e transitórias. Essas diretrizes contribuíram para impulsionar a elaboração do Plano Diretor de Desenvolvimento Integrado (PDDI) (SECID; IMESC, 2018), que tem como finalidade balizar as políticas públicas sobre as Funções Públicas de Interesse Comum (FPICs) entre os 13 municípios da RMGSL.

Segundo as diretrizes, a implantação de uma gestão mais ativa na RMGSL tem como finalidade fortalecer, através da colaboração, articulação e integração entre o estado e os municípios da região metropolitana, os seguintes benefícios: otimização dos potenciais e oportunidades de desenvolvimento e a disseminação dos seus efeitos em nível estadual; redução das desigualdades sociais e econômicas entre os municípios e entre os segmentos sociais; justa distribuição dos benefícios e ônus decorrentes do processo de metropolização; consolidação da consciência e identidade metropolitana; e gestão democrática e controle social.

No entanto, a aplicabilidade desses benefícios não é tão simples. A problemática da desigualdade socioeconômica no espaço da própria RMGSL é produto de anos de territorialização submissa aos interesses do capital em detrimento dos interesses coletivos. O resultado é a materialização de infraestruturas urbanas precárias ou, inclusive, a ausência de equipamentos essenciais, como aqueles que compõem o sistema de rede bancária. As disparidades entre os segmentos sociais intermunicipais devem ser as primeiras a serem solucionadas no sentido de definir uma condição metropolitana comum. A discrepância interna resulta na desigualdade entre os municípios, como se pode 
observar nos dados relativos ao IDHM (2010), ao IVS (2010), à renda per capita (2010) e ao PIB (2018) (Tabela 1).

Tabela 1 - RMGSL: população, IDHM, IVS, renda per capita e PIB dos municípios (2010)

\begin{tabular}{l|c|c|c|c|c}
\hline \multicolumn{1}{c|}{ Município } & População & IDHM & IVS & $\begin{array}{c}\text { Renda per } \\
\text { capita (R\$) }\end{array}$ & $\begin{array}{c}\text { PIB per } \\
\text { capita (2018) }\end{array}$ \\
\hline Alcântara & 21.851 & 0,573 & 0,570 & 241,1 & $5.880,13$ \\
\hline Axixá & 11.407 & 0,641 & 0,563 & 242,1 & $6.127,36$ \\
\hline Bacabeira & 14.925 & 0,629 & 0,504 & 285,7 & $18.224,09$ \\
\hline Cachoeira Grande & 8.446 & 0,537 & 0,695 & 132,4 & $5.879,75$ \\
\hline Icatu & 25.145 & 0,546 & 0,759 & 182,5 & $5.795,84$ \\
\hline Morros & 17.783 & 0,548 & 0,640 & 190,9 & $6.451,76$ \\
\hline Paço do Lumiar & 105.121 & 0,724 & 0,443 & 474,0 & $7.733,25$ \\
\hline Presidente Juscelino & 11.541 & 0,563 & 0,658 & 156,9 & $6.899,3$ \\
\hline Raposa & 26.327 & 0,626 & 0,642 & 293,7 & $7.838,23$ \\
\hline Rosário & 39.576 & 0,632 & 0,526 & 297,5 & $8.426,98$ \\
\hline Santa Rita & 32.366 & 0,609 & 0,544 & 270,9 & $7.226,98$ \\
\hline São José de Ribamar & 163.045 & 0,708 & 0,449 & 471,5 & $12.366,97$ \\
\hline São Luís & 1.014 .837 & 0,768 & 0,372 & 855,3 & $30.699,57$ \\
\hline RMGSL (média) & $\mathbf{1 . 4 9 2 . 3 7 0}$ & $\mathbf{0 , 6 2 3}$ & $\mathbf{0 , 5 6 7}$ & $\mathbf{3 1 5 , 0}$ & $\mathbf{1 2 9 . 5 5 0 , 2 1}$ \\
\hline
\end{tabular}

Elaborada por Magno Vasconcelos Pereira Junior com base em AtlasBR (2013), IBGE (2010) e IPEA (2018).

Quanto maior o IDHM, melhores são as condições vida; enquanto a relação é inversa no caso do IVS: quanto maior seu valor, piores as condições de vida. Ademais, é importante ressaltar que o IDHM trabalha com três dimensões: a expectativa de vida, que está relacionada diretamente com a saúde; o acesso ao conhecimento, vinculado à educação; e o padrão de vida, que se refere ao poder de compra medido pelo rendimento médio. Por seu turno, o IVS trabalha com a média de três subíndices: a infraestrutura urbana, o capital humano e a renda de trabalho.

Constata-se na Tabela 1 que as disparidades socioeconômicas e espaciais são significativas. São Luís detém os melhores indicadores, bastante superiores aos dos demais municípios da RMGSL. Por exemplo, a renda per capita de Paço do Lumiar (R\$474), o segundo melhor colocado quanto a esse indicador, é praticamente a metade daquela da capital ( $\mathrm{R} \$$ 855). Cachoeira Grande e Presidente Juscelino apresentam as menores rendas per capita da RMGSL, respectivamente R \$ 132,4 e $\mathrm{R} \$ 156,9$. Por outro lado, o PIB per capita, a soma total dos bens e serviços finais produzidos, também revela uma discrepância: São Luís, que conta com um PIB per capita de $\mathrm{R} \$ 30.699,57$, ou seja, indicando o que cada pessoa produziu, detém 
quase um quarto de todo o PIB da RMGSL, contrastando com Icatu (R \$ 5.795,84), Cachoeira Grande ( $\mathrm{R} \$ 5.879,75)$ e Alcântara $(\mathrm{R} \$ 5.880,13)$, os menores da região, demonstrando a baixa concentração de bens e serviços nesses espaços.

Os indicadores sociais, como o IDHM e o IVS, também evidenciam essa realidade. O IDHM de São Luís $(0,768)$ é superior aos dos outros 12 municípios, embora aqueles mais próximos à capital também apresentem bons indicadores, como Paço do Lumiar (0,724) e São José de Ribamar (0,708). O município de Raposa, mesmo estando situado na mesma Ilha da capital, é o que mais se distancia dela e, de certa forma, o que menos usufrui dos bens e serviços por ela oferecidos. Mesmo tendo o menor $\operatorname{IDHM}(0,626)$ dentre os quatro municípios da Ilha, ainda assim o seu valor é superior ao de muitos municípios que estão no continente. Esse padrão se repete no que diz respeito ao IVS: os municípios da Ilha têm melhores indicadores, enquanto a maior parte dos municípios que está mais distante da capital apresenta maior vulnerabilidade social, como é o caso de Icatu, cujo IVS de 0,759 é o pior de toda a RMGSL.

A realidade acima é ratificada quando se analisa o IVS em infraestrutura urbana. Esse indicador procura refletir as condições de acesso a serviços de saneamento básico e de mobilidade urbana. Neste ponto, visualizamos apenas as infraestruturas por domicílio em porcentagem de saneamento básico, que é composta por três pilares: coleta de lixo, abastecimento de água e esgotamento (Tabela 2).

Tabela 2 - RMGSL: percentual municipal de ausência de coleta de lixo, abastecimento de água e esgotamento por domicílio (2010)

\begin{tabular}{l|c|c|c}
\hline \multicolumn{1}{c|}{ Municípios } & $\begin{array}{c}\text { Sem coleta de } \\
\text { lixo adequado }\end{array}$ & $\begin{array}{c}\text { Sem abastecimento } \\
\text { de rede geral de água }\end{array}$ & $\begin{array}{c}\text { Sem esgotamento } \\
\text { adequado }\end{array}$ \\
\hline Alcântara & $\mathbf{7 7 , 7 7}$ & 42,46 & 99,1 \\
\hline Axixá & 89,12 & 35,21 & 99,4 \\
\hline Bacabeira & 48,04 & 33,17 & 99,3 \\
\hline Cachoeira Grande & 77,74 & 85,37 & 99,9 \\
\hline Icatu & 84,64 & 58,62 & 99,6 \\
\hline Morros & 69,99 & 66,25 & 98,9 \\
\hline Paço do Lumiar & 38,47 & 35,66 & 70,5 \\
\hline Presidente Juscelino & 82,56 & 69,47 & 99,8 \\
\hline Raposa & 49,36 & 21,50 & 98,7 \\
\hline Rosário & 43,16 & 39,49 & 98,0 \\
\hline Santa Rita & $\mathbf{6 8 , 7}$ & 39,11 & 99,8 \\
\hline São José de Ribamar & $\mathbf{1 8 , 9 6}$ & $\mathbf{3 4 , 9}$ & 90,3 \\
\hline São Luís & 8,84 & 23,64 & 53,3 \\
\hline RMGSL (média) & $\mathbf{5 8 , 2 6}$ & $\mathbf{4 4 , 9 9}$ & $\mathbf{9 2 , 8 1}$ \\
\hline
\end{tabular}

Elaborada por Magno Vasconcelos Pereira Junior com base em IBGE (2010). 
Os serviços tidos como adequados quanto ao lixo correspondem àqueles que possuem coleta regular, e, os de abastecimento de água, os realizados pela rede geral. O esgotamento foi considerado satisfatório para o caso daqueles domicílios que têm rede de esgoto, excluindo-se residências que utilizam fossa séptica e outras soluções de esgotamento pouco adequadas.

As diferenças socioespaciais entre os municípios da RMGSL mais uma vez são ratificadas pelos dados levantados. Somente $8,84 \%$ dos domicílios em São Luís não dispõem de coleta de lixo, enquanto o segundo e o terceiro melhores indicadores, os de São José de Ribamar e de Paço do Lumiar, são, respectivamente de $18,96 \%$ e 38,47\%; valores entre duas a quatro vezes maiores que o do primeiro colocado. O município mais vulnerável é o de Axixá, apresentando 89,12\% dos domicílios sem a coleta de lixo; precariedade esta que contribui para alastrar doenças e elevar problemas de saúde em contexto metropolitano.

Dentre os indicadores de saneamento básico, o de melhor desempenho é o abastecimento de água. O município de Raposa, seguido por São Luís, são os dois que apresentam condições mais favoráveis, contando, respectivamente, com apenas 21,5\% e 23,64\% das casas não cobertas pelo sistema. O município mais prejudicado é Cachoeira Grande, no qual 85,37\% das casas não têm água encanada, tendo que recorrer a poços ou rios para adquirir esse elemento vital para a sobrevivência humana.

Os dados mais alarmantes são os referentes ao esgotamento. De certa forma, existe uma homogeneidade entre os municípios da RMGSL quanto a esse indicador, pois quase todos não têm o serviço devidamente ofertado. A maioria apresenta percentuais entre $90 \%$ a $99 \%$ de domicílios sem a oferta do referido serviço. Os melhores desempenhos são os de São Luís, com 53,3\%, e Paço do Lumiar, com 70,5\%. Tais dados reforçam a gravidade da falta dessa infraestrutura urbana e o desafio colocado à gestão pública para a reversão desse quadro.

Diante disso, pode-se verificar que as disparidades socioespaciais estão fortemente presentes na RMGSL, reflexo da concentração de renda em determinados espaços, de formas de segregação socioespacial, de diferenciações na oferta de serviços e infraestruturas urbanas e da desigualdade de oportunidades quanto às formas de reprodução social, que são bem mais favoráveis na capital do estado que nos demais municípios tidos como metropolitanos.

\subsection{METROPOLIZAÇÃO DE BELÉM}

A partir de 1991, a população rural do estado do Pará oficialmente considerada passa a ser menor que a população urbana (Figura 2), o que contribui 
para intensificar e acelerar os processos de crescimento das cidades. Esse período traz mudanças quantitativas significativas, mas também qualitativas. A urbanização ganha novo conteúdo e nova dinâmica, graças às diversas modalidades do impacto da modernização sobre o território (SANTOS, 2008), ainda que em níveis e formas diferentes para cada região do Brasil.

Figura 2 - Pará: população urbana e rural (1960-2010)

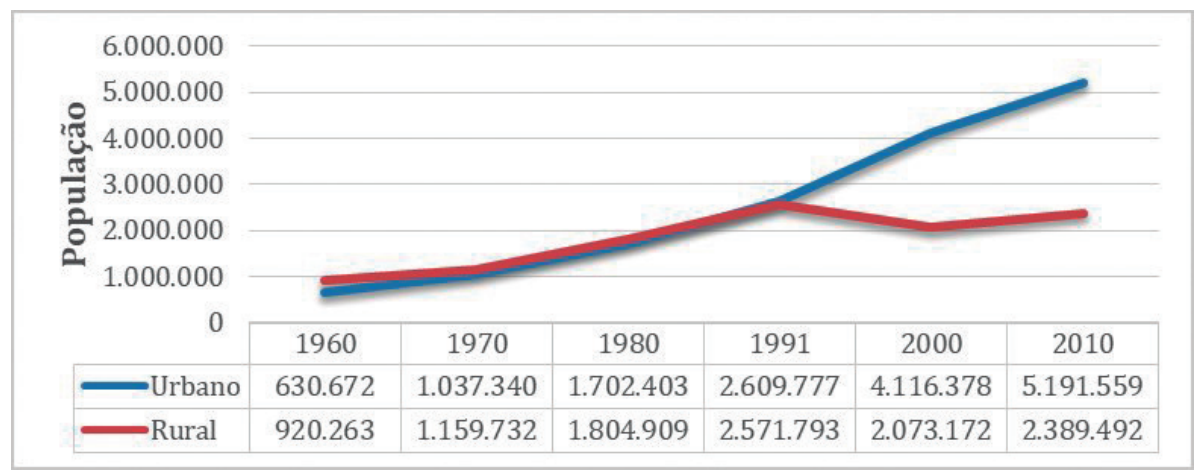

Elaborada por Magno Vasconcelos Pereira Junior com base em IBGE (2010, [1960] 2021a, [1970] 2021b, [1980] 2021c, [1991] 2021d, [2000] 2021e).

O processo de urbanização na região Norte se destacou pelas estratégias do governo federal para a ocupação da Amazônia. A modernização dos setores econômicos foi um forte aliado nessa tarefa, com a transformação do Banco de Crédito da Borracha em Banco da Amazônia (BASA) e da Superintendência do Plano de Valorização Econômica da Amazônia (SPVEA) em Superintendência de Desenvolvimento da Amazônia (SUDAM), instituições que contribuíram para as políticas desenvolvimentistas e adensamento populacional nas cidades.

Ademais, foi criada a Zona Franca de Manaus (ZFM), um enclave industrial em meio à economia extrativista. Segundo Santos (2015), a ZFM é um modelo de desenvolvimento econômico implantado pelo governo brasileiro com o objetivo de viabilizar uma base econômica na Amazônia ocidental e promover a integração produtiva da região ao País. Nesse período também foi inaugurada, em 1960, a Rodovia Belém-Brasília, com a finalidade de ligar a região Norte à região CentroOeste. A integração geográfica permitiu o escoamento da produção e, ao mesmo tempo, um acesso mais favorável à mobilidade populacional. Ao final, o projeto geopolítico auxiliou na produção do espaço, acelerou o processo de urbanização e territorializou os grandes capitais por meio da nova ocupação regional.

A produção do espaço relacionada precipuamente aos interesses econômicos das diversas formas de capital que passaram a definir os rumos do 
chamado desenvolvimento regional, resultou, em contrapartida, no baixo nível do investimento na infraestrutura urbana em face do superdimensionamento dos processos que passaram a definir a vida nas cidades, configurando deficiências de infraestrutura, de serviços essenciais e de oferta de empregos de acordo com a demanda da população expropriada do espaço agrário e dos novos migrantes que chegavam à região atraídos pelas políticas desenvolvimentistas:

a Amazônia tornou-se uma floresta urbanizada, com 61\% da população em 1996 vivendo em núcleos urbanos, apresentando ritmo de crescimento superior ao das demais regiões do país a partir de 1970, e uma desconcentração urbana, na medida em que cresceu a população não mais apenas nas capitais estaduais, mas nas cidades de menos de 100.000 habitantes. É verdade que as cidades se tornaram um dos maiores problemas ambientais da Amazônia, dadas a velocidade da imigração e a carência de serviços. Mas são também importante mercado regional (BECKER, 2001, p. 140).

Tal processo demarcou a metropolização de Belém. Com a nova lógica, houve incremento e redefinição da dinâmica territorial, que envolveu novas redes de circulação, comunicação e infraestrutura para a expansão das novas frentes econômicas e o incremento dos fluxos de mão de obra, capital e informação. Os rios, historicamente importantes para o surgimento de várias cidades amazônicas, passaram a ser relativamente substituídos ou complementados por novas conexões de transporte, especialmente as rodoviárias, que encurtaram as distâncias e o tempo de locomoção, apesar de muitas delas apresentarem péssimos estados de manutenção. O início da metropolização de Belém ocorre nesse contexto:

[...] faz parte de um momento em que a região amazônica passa a vivenciar as transformações decorrentes de sua efetiva integração econômica ao Nordeste e ao Centro-Sul do País - tendo como um dos marcos desse processo a inauguração da Rodovia Belém-Brasília (TRINDADE JÚNIOR, 1998, p. 40).

Desse modo, entende-se que a integração rodoviária e econômica da região amazônica, vivenciada a partir da década de 1960, constitui um elemento fundamental para compreender a dinâmica da produção do espaço urbano da capital paraense e, consequentemente, o surgimento da Região Metropolitana de Belém, como explica Santos (2015):

é possível entender a metropolização regional a partir do desenvolvimento da infraestrutura que possibilitou o projeto de integração da Amazônia ao restante da economia nacional via articulação dessas redes rodoviárias. As mudanças no papel da região também tiveram repercussões na produção do espaço urbano de Belém que, até a década de 1960, estava limitada fisicamente (SANTOS, 2015, p. 110-111). 
Diante das alterações na configuração espacial regional, foi institucionalizada a Região Metropolitana de Belém, em 8 de junho de 1973, pela Lei Complementar no 14 (BRASIL, 1973), abrangendo dois municípios: Belém e Ananindeua. Posteriormente, houve mais três leis complementares que alteraram sua área de abrangência (Quadro 2).

Quadro 2 - RMB: municípios integrantes de acordo com as leis complementares

\begin{tabular}{|l|l|}
\hline Lei Complementar & \multicolumn{1}{|c|}{ Municípios } \\
\hline$N^{\circ} 14 / 1973$ & Belém, Ananindeua \\
\hline$N^{o} 27 / 1995$ & Belém, Ananindeua, Benevides, Marituba, Santa Bárbara \\
\hline$N^{o} 72 / 2010$ & $\begin{array}{l}\text { Belém, Ananindeua, Benevides, Marituba, Santa Bárbara, Santa } \\
\text { Izabel do Pará }\end{array}$ \\
\hline$N^{o} 76 / 2011$ & $\begin{array}{l}\text { Belém, Ananindeua, Benevides, Marituba, Santa Bárbara e Santa } \\
\text { Izabel do Pará, Castanhal }\end{array}$ \\
\hline
\end{tabular}

Elaborado por Magno Vasconcelos Pereira Junior com base em Brasil (1973) e Pará ([1995] s. d., 2010, 2011).

Por um período de vinte e dois anos, a RMB foi composta somente por dois municípios, o que, de certa forma, mostra a importância deles para a configuração metropolitana atual. Atualmente, conforme estabelecido pela Lei Complementar Estadual no 76/2011 (PARÁ, 2011), a RMB é composta por sete municípios: Belém, Ananindeua, Benevides, Marituba, Santa Bárbara, Santa Izabel do Pará e Castanhal. Essa grande malha é constituída espacialmente por uma área continental e um conjunto insular com mais de 40 ilhas (CARDOSO et al., 2006).

A área mais densamente ocupada é definida pela conurbação que se consolidou desde os primeiros momentos do processo de metropolização e que, ainda hoje, representa a área que mais concentra a oferta de empregos e serviços. O Mapa 2 mostra os municípios integrantes da região metropolitana oficial.

Em seu processo de formação histórica é possível perceber três principais momentos da dinâmica socioespacial da RMB: o que define uma forma compacta, o que configura uma forma dispersa, e a atual, que aponta para uma estrutura mais difusa (TRINDADE JÚNIOR, 2019).

Inicialmente, na gênese da forma metropolitana, definiu-se um processo de metropolização mais compacto, concentrando a urbanização e seus processos nas áreas centralizadas, especialmente no município de Belém. Nesse momento, as áreas de baixadas, com condições topográficas alagáveis ou sujeitas a alagamentos, tornaram-se espaços de grande dinamismo por abrigarem as populações pobres por meio de vários processos de ocupação e de conflitos urbanos; processos esses que foram responsáveis por adensar a metrópole em formação nas suas áreas mais centrais (TRINDADE JÚNIOR, 1998, 2019). 
Mapa 2 - RMB: composição e ano de inclusão legal dos municípios

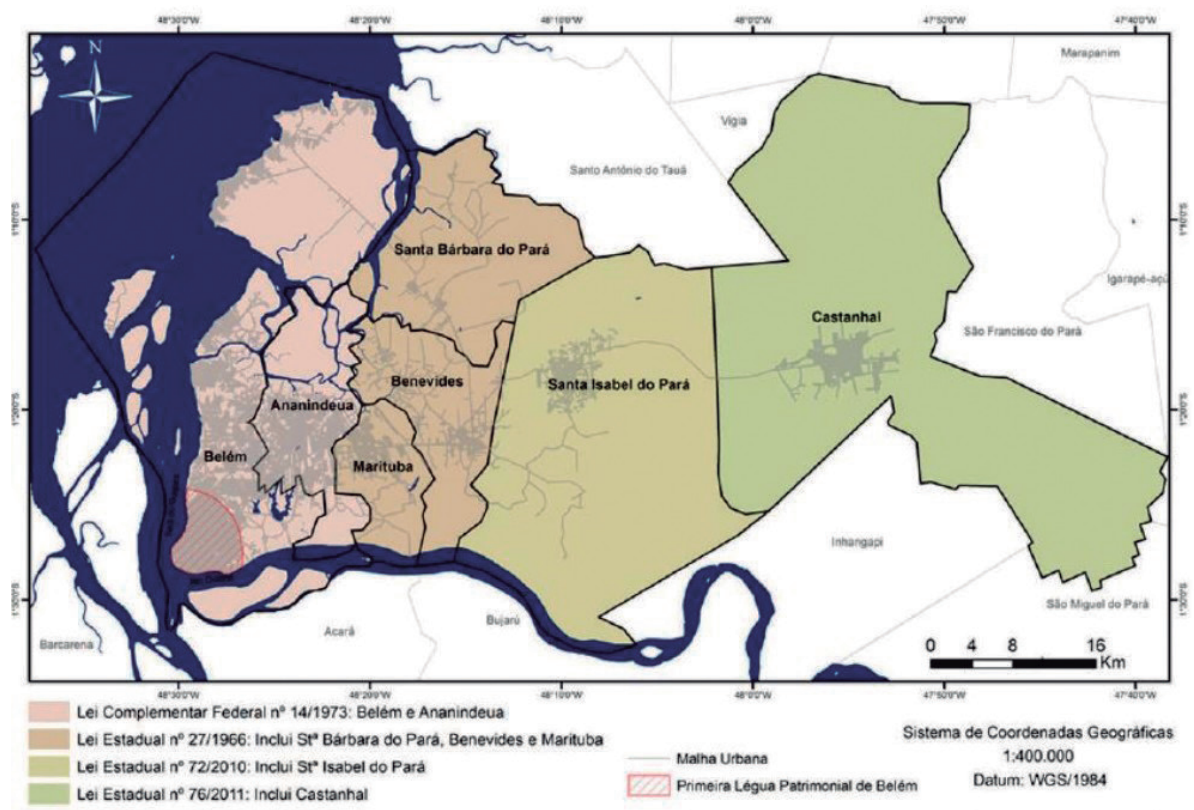

Fonte: SEDOP (2018).

O segundo momento está relacionado à dispersão da população de baixa renda, que passou a ocupar as áreas periféricas mais distantes em dois principais vetores de expansão, um dentro do próprio município de Belém e outro rumo a municípios vizinhos (Ananindeua, Marituba e Benevides, principalmente). Esse processo está relacionado aos investimentos nas áreas mais centrais, à política oficial de moradia e ao déficit habitacional que desencadeou uma nova onda de ocupações espontâneas nesses novos vetores de expansão urbana, ao mesmo tempo em se promovia a expulsão, forçada pelo Estado ou por meio da lógica de mercado, da população pobre das áreas mais centrais de Belém (TRINDADE JÚNIOR, 1998).

$\mathrm{Na}$ tendência mais atual, entretanto, verifica-se um processo de difusão urbana, que não se define necessariamente por uma malha contínua e que tende a extrapolar mesmo os limites do espaço metropolitano oficial, ainda que sob um modelo precarizado de urbanização, com flagrantes espaços de exclusão social e de pobreza urbana. Na configuração metropolitana que se anuncia, além dos dois vetores de expansão urbana observados no período anterior, um outro pode ser visualizado, rumo a municípios até agora não integrantes da malha metropolitana oficial. Trata-se de uma tendência mais pulverizada de metropolização, cuja 
unidade é dada principalmente por fluxos e coesão que conferem unidade metropolitana de movimentos e processos e uma estrutura metropolitana mais complexa (TRINDADE JÚNIOR, 2019).

$\mathrm{O}$ atual momento caracteriza-se, sobretudo, pela reafirmação das estratégias de reapropriação das áreas centrais por classes solventes, pelo surgimento de novos eixos fora dos espaços centrais, pela expansão urbano-imobiliária pulverizada voltada a estratos sociais diferenciados para além de Belém e da região metropolitana oficial, pela dispersão e pulverização da pobreza no tecido metropolitano e pela configuração de uma metrópole ampliada e descontínua com raio de alcance considerável (TRINDADE JÚNIOR, 2019).

Para analisar as discrepâncias socioespaciais que existem no interior da RMB, utilizam-se os mesmos critérios adotados para a RMGSL, a saber, o IDH, o IVS, a renda per capita e o PIB dos municípios que integram a região metropolitana oficialmente reconhecida (Tabela 3).

Tabela 3 - RMB: população, IDHM, IVS, renda per capita e PIB dos municípios (2010)

\begin{tabular}{l|r|r|r|r|r}
\hline \multicolumn{1}{c|}{ Municípios } & População & IDHM & \multicolumn{1}{c|}{ IVS } & $\begin{array}{r}\text { Renda per } \\
\text { capita (R\$) }\end{array}$ & $\begin{array}{c}\text { PIB } \text { per } \\
\text { capita (2018) }\end{array}$ \\
\hline Belém & 1.393 .399 & 0,746 & 0,317 & 901,10 & $21.191,47$ \\
\hline Ananindeua & 471.980 & 0,718 & 0,377 & 594,60 & $14.314,96$ \\
\hline Benevides & 51.651 & 0,665 & 0,457 & 417,20 & $25.772,35$ \\
\hline Marituba & 108.246 & 0,676 & 0,455 & 406,50 & $14.706,60$ \\
\hline Santa Bárbara & 17.141 & 0,627 & 0,487 & 322,30 & $8.325,10$ \\
\hline Santa Isabel do Pará & 59.466 & 0,659 & 0,385 & 415,30 & $10.867,42$ \\
\hline Castanhal & 173.149 & 0,673 & 0,351 & 498,40 & $19.728,13$ \\
\hline RMB (média) & $\mathbf{2 . 2 7 5 . 0 3 5}$ & $\mathbf{0 , 6 8 1}$ & $\mathbf{0 , 4 0 4}$ & $\mathbf{5 0 7 , 9 1}$ & $\mathbf{1 6 . 4 1 5 , 1 5}$ \\
\hline
\end{tabular}

Elaborada por Magno Vasconcelos Pereira Junior com base em AtlasBR (2013), IBGE (2010) e IPEA (2018).

A Tabela 3 mostra uma desigualdade socioeconômica entre os municípios ao se comparar os indicadores selecionados. A capital paraense detém a melhor renda per capita dentre os municípios, com $\mathrm{R} \$ 901,1$. A discrepância é evidente quando se compara esse valor ao do segundo mais bem colocado, Ananindeua, que detém uma renda per capita de $\mathrm{R}$ \$594,60. Mais evidente ainda se torna a discrepância se compararmos esse mesmo indicador de Belém com o do município de pior performance, Santa Bárbara, com apenas R \$322,30.

Ao se interpretar os dados do PIB per capita, que resulta da divisão de toda a produção de bens e serviços no município pelo total da população residente, 
observa-se menor disparidade entre alguns municípios, notadamente os que estão mais bem posicionados nesse indicador (Benevides e Belém, respectivamente), que mantêm uma diferença de 21,62\%.

O fato de Benevides ter o maior PIB per capita permite concluir que existe uma espécie de superávit da produtividade de bens e serviços em relação à absorção da mão de obra local. Isso porque sua distribuição de renda apresenta valor intermediário no contexto da RMB, apesar de ter o maior PIB per capita; ou seja, é possível que exista um forte pêndulo migratório de pessoas de outros municípios que vão trabalhar em Benevides, já que este possui importantes unidades empregadoras, como o complexo industrial Ecoparque, da empresa Natura.

Não obstante a performance de Benevides quanto ao PIB percapita, os outros dados permitem concluir que o dinamismo da economia local não necessariamente encontra correspondência em termos de qualidade de vida, pois esse município apresenta um baixo IDHM e um baixo IVS, situando-se na antepenúltima posição em relação a esses índices dentre os municípios integrantes da RMB.

Em relação aos indicadores apresentados, é de se notar que a capital paraense detém os melhores números do IDHM e do IVS. Quanto maior o valor do primeiro, melhores são as condições de vida; quanto menor o valor do segundo, menos vulnerável encontra-se a sociedade. O pior desempenho é o do município de Santa Bárbara, que, apesar da sua proximidade com Belém, apresenta carência de equipamentos que poderiam melhorar a qualidade de vida da população local.

Quanto às infraestruturas, foram recopilados e analisados os dados (Tabela 4) a partir da mesma metodologia já descrita anteriormente para São Luís, levando-se em conta o Índice de Vulnerabilidade Social em Infraestrutura Urbana (IVS-I) para demonstrar e reforçar a ideia da existência de desigualdade interna entre os municípios da RMB.

Os dados da Tabela 4 demonstram os problemas enfrentados pelos municípios da RMB e como afetam o padrão de vida e o bem-estar social dos seus habitantes. Em particular, Santa Bárbara aparece como o mais socialmente vulnerável, com 47,44\% das moradias não atendidas por coleta de lixo adequada, realizada pelo sistema de limpeza municipal.

Quanto ao abastecimento de água, Ananindeua é o que apresenta a maior deficiência. 63,8\% do total de 125.800 mil domicílios permanentes existentes no município não conta com abastecimento oficial de água. Somente 45.540 mil domićlios estão ligados por rede geral, enquanto os demais, 80.260 mil domicílios, abastecem-se por meio de poço artesiano, água da chuva, dos lagos, dos rios, igarapé etc. (IBGE, 2010). 
Tabela 4-RMB: percentual municipal de ausência de coleta de lixo, abastecimento de água e esgotamento por domicílio (2010)

\begin{tabular}{l|r|r|r}
\hline \multicolumn{1}{c|}{ Municípios } & $\begin{array}{c}\text { Sem coleta de } \\
\text { lixo adequado }\end{array}$ & $\begin{array}{c}\text { Sem abastecimento } \\
\text { de rede geral de água }\end{array}$ & $\begin{array}{c}\text { Sem esgotamento } \\
\text { adequado }\end{array}$ \\
\hline Ananindeua & 2,25 & 63,80 & 88,49 \\
\hline Belém & 3,28 & 24,51 & 62,37 \\
\hline Benevides & 14,58 & 30,36 & 98,72 \\
\hline Castanhal & 9,73 & 54,83 & 96,42 \\
\hline Marituba & 10,66 & 61,24 & 95,75 \\
\hline Santa Bárbara & 47,44 & 32,11 & 99,00 \\
\hline Santa Isabel do Pará & 25,55 & 34,82 & 99,11 \\
\hline RMB (média) & $\mathbf{1 6 , 2 1}$ & $\mathbf{4 3 , 1 0}$ & $\mathbf{9 1 , 4 1}$ \\
\hline
\end{tabular}

Elaborada por Magno Vasconcelos Pereira Junior com base em IBGE (2010).

Cabe notar que os dados correspondem somente aos serviços considerados oficialmente aptos, não se levando em conta aqueles tidos como inadequados, a exemplo da queima e dos aterros de lixos, da coleta de água que não seja da rede estadual, dos poços, dos rios e dos lagos.

Para a rede de esgoto, os critérios utilizados foram os mesmos da RMGSL. Foram desconsideradas para esta análise as fossas sépticas, formas rudimentares de esgotamento sanitário, valas, entre outras que não estão inseridas no sistema de rede do estado. Por isso esse índice se apresenta como um dos mais problemáticos em razão da elevada ausência de esgotamento nos municípios considerados, uma vez que a maioria deles apresenta déficits muito elevados, acima de 90\%. Belém e Ananindeua apresentam percentuais relativamente inferiores, com respectivamente $62,37 \%$ e $88,49 \%$ dos domicílios sem esgotamento sanitário; o que não exclui a consideração de que estes também são números preocupantes.

Os dados apresentados confirmam que o município de Belém apresenta um melhor desempenho em relação aos demais e detém os melhores indicadores, tanto sociais como econômicos. Isso se explica porque, via de regra, a capital tende a concentrar os maiores investimentos pela importância política e econômica que desempenha.

\section{CONSIDERAÇÕES FINAIS}

Os dados estatísticos apresentados pelos indicadores utilizados no presente artigo têm um papel fundamental nas análises dos territórios, das desigualdades sociais e econômicas, no intuito de mensurar o tamanho das 
problemáticas enfrentadas pelas regiões metropolitanas. No entanto, também apresentam limitações, pois, por si sós, não informam a origem dos fenômenos e suas causas de forma mais profunda, as razões da distribuição irregular dos equipamentos urbanos ou os interesses subjacentes ao beneficiamento de certas áreas em detrimento de outras.

É nesse sentido que se faz importante um estudo multidisciplinar para interpretação desses dados e que ajudam a entender a constante e ininterrupta metamorfose dos espaços urbanos. A análise das Regiões Metropolitanas de Belém e de São Luís, realizada neste artigo, buscou suprir essas limitações por meio de estudos bibliográficos e documentais.

Isto posto, o tema da metropolização assume um papel essencial na dinâmica territorial. Dessa forma, a região metropolitana deve ser entendida como uma dimensão importante do espaço político-administrativo institucionalizado para fins de planejamento. Não se pode confundi-la com uma mera aglomeração urbana. Isso porque ela pressupõe "a difusão no espaço de atividades, das funções e dos grupos, e sua interdependência segundo uma dinâmica social amplamente independente da ligação geográfica” (CASTELLS, p. 53, 1983).

A partir dos dados analisados, entende-se que as Regiões Metropolitanas de Belém e de São Luís apresentam elementos de formação que se aproximam e que dizem respeito ao processo de produção do espaço maior em que se inserem pela ação do capital e das políticas governamentais implementadas, e que seus problemas, ainda que configurem particularidades, revelam um padrão de metropolização relativamente similar, constatado pelas desigualdades socioespaciais internas e pela concentração, mesmo que precária, de serviços e infraestrutura nas cidades principais, que são as capitais estaduais.

Em que pesem essas similaridades, também há diferenciações a serem demarcadas. A RMB é constituída de sete municípios e a RMGSL, de treze. No primeiro caso, o processo de metropolização vai muito além da região metropolitana oficial. O mesmo não acontece com a segunda, que parece constituir uma região metropolitana aquém do que é tido como oficial.

A região metropolitana de Belém, mesmo com um menor número de municípios, é mais populosa, 34,4\% a mais que a de São Luís. No entanto, o PIB per capita desta última no ano de 2018 foi bem superior que o da primeira, como apresentado nas Tabelas 1 e 3, chegando a $\mathrm{R} \$ 129.550,21$ contra os $\mathrm{R} \$ 16.415,15$ de Belém. Isso significa que a dinâmica produtiva é mais intensa na RMGSL, devido aos grandes complexos industriais que se instalaram na região, como o da Alumar, da Vale S.A., e também devido ao Porto do Itaqui. 
Porém, como mencionado anteriormente, a produtividade do capital nem sempre representa uma melhor qualidade de vida e bem-estar social. Neste caso, é confirmado que a RMB, apesar da precariedade de seus índices, apresenta melhores indicadores sociais do que a RMGSL, como se pode observar pela comparação das suas médias de IDHM e de IVS, que são, respectivamente, de 0,681 e 0,404 para a RMB e de 0,623 e 0,567 para a RMGSL. A desigualdade entre esses dois grupos é mais visível no IVS, índice que engloba a infraestrutura urbana, o capital humano, a renda e o trabalho, e cuja diferença é de 0,163 pontos. Ou seja, a RMGSL é 40,35\% mais vulnerável no que se refere a esses requisitos.

Ademais, o indicador renda per capita expõe uma diferença significativa entre as duas regiões metropolitanas. Enquanto a RMB apresenta o valor de R\$ 507,91 para esse indicador, a RMGSL conta com R \$315,0, o que evidencia uma diferença de 61,25\% entre elas. Pode-se afirmar, neste caso, que a análise dos indicadores IDHM, IVS e renda per capita reforçou a ideia de que nem sempre o crescimento do PIB traduz-se em um desenvolvimento socioespacial compatível com a riqueza que está sendo localmente produzida.

A diferença entre as duas também é reproduzida nas infraestruturas básicas. $\mathrm{O}$ indicador mais representativo disso é a coleta dos resíduos sólidos. $\mathrm{Na} \mathrm{RMB}$, apenas $16,21 \%$ dos domicílios não são atendidos pela coleta feita pelas prefeituras, enquanto na RMGSL são 58,26\% dos domicílios que não são contemplados por esse serviço. Os números são do ano de 2010 e, em 2018, o município de São Luís, fez um acordo intermunicipal para solucionar a problemática dos resíduos sólidos, o que pode ter alterado parcialmente esse panorama.

Os dados também apontam que o esgotamento sanitário é deficitário em ambas as regiões metropolitanas. $\mathrm{Na} \mathrm{RMB}, 91,41 \%$ dos domicílios não possuem rede adequada para escoar seus resíduos, enquanto na RMGSL o percentual chega a 92,81\%. A média brasileira quanto a esse serviço é de 44,55\%. O baixo desempenho das duas regiões metropolitanas preocupa e tem repercussões sociais e ambientais, comprometendo o padrão de vida da população, especialmente daquela sua porção mais vulnerável.

Por fim, as regiões metropolitanas, como regiões de planejamento que são, precisam avançar em políticas públicas urbanas que possibilitem amenizar tais índices e reduzir as desigualdades intrametropolitanas, que reforçam a condição do espaço socialmente produzido como resultado e, ao mesmo tempo, como condição de reprodução das desigualdades sociais, conforme pudemos perceber na diferenciação dos índices das cidades principais em relação ao conjunto das regiões metropolitanas das quais fazem parte, onde os demais munícipios tendem assumir o perfil de espaços segregados de reduzido padrão de vida. 


\section{REFERÊNCIAS}

ATLASBR. Desenvolvimento humano. Atlas do Desenvolvimento Humano no Brasil, [s. l.], 2013. Disponível em: http://www.atlasbrasil.org.br/consulta/ planilha. Acesso em: 21 jun. 2020.

BECKER, B. K. Revisão das políticas de ocupação da Amazônia: é possível identificar modelos para projetar cenários? Parcerias Estratégicas, Brasília, DF, v. 6, n. 12, p. 135-159, set. 2001.

BRASIL. Lei Complementar $\mathbf{N}^{\mathbf{0}} \mathbf{1 4}$, de 08 de junho de 1973. Estabelece as regiões metropolitanas de São Paulo, Belo Horizonte, Porto Alegre, Recife, Salvador, Curitiba, Belém e Fortaleza. Brasília, DF: Casa Civil, 1973. Disponível em: http://www.planalto.gov.br/ccivil_03/leis/LCP/Lcp14.htm. Acesso em: 10 jan. 2020.

BURNETT, F. L. Da cidade unitária à metrópole fragmentada, crítica à constituição da São Luís moderna. In: SEMINÁRIO DE HISTÓRIA DA CIDADE E DO URBANISMO, 9., 2006, São Paulo. Anais [...]. São Paulo: [s. n.], 2006. p. 1-10.

CAPEL, H. La definición de lo urbano. Estudios Geográficos, Barcelona, n. 138/139, p. 265-301, feb./mayo 1975. Disponível em: http://www.ub.edu/ geocrit/sv-33.htm. Acesso em: 28 mar. 2021.

CARDOSO, A. C. D. et al. A estrutura socioespacial da região metropolitana de Belém: de 1990 a 2000. Novo Cadernos NAEA, Belém, v. 10, n. 1, p. 143-183, dez. 2006

CASTELLS, M. A questão urbana. Tradução Arlete Caetano. Rio de Janeiro: Paz e Terra, 1983. 506 p.

HARVEY, D. Espaços de esperança. São Paulo: Loyola, 2004.

IBGE. Censo demográfico: 2010. IBGE, Rio de Janeiro, 2010. Disponível em: https://censo2010.ibge.gov.br. Acesso em: 21 jul. 2020.

IBGE. Pesquisa territorial: 2016. IBGE, Rio de Janeiro, 2016. Disponível em: https://sidra.ibge.gov.br/territorio. Acesso em: 08 jul. 2020.

IBGE. Pesquisa territorial: 2020. IBGE, Rio de Janeiro, 2020. Disponível em: https://sidra.ibge.gov.br/territorio. Acesso em: 08 jul. 2020.

IBGE. Censo demográfico: 1960. IBGE, Rio de Janeiro, 2021a.

Disponível em: https://biblioteca.ibge.gov.br/index.php/

bibliotecacatalogo?id=768\&view=detalhes. Acesso em: 20 jul. 2020. 
IBGE. Censo demográfico: 1970. IBGE, Rio de Janeiro, 2021b. Disponível em: https:/ / biblioteca.ibge.gov.br/biblioteca-catalogo.html?id=769\&view=detalhes. Acesso em: 20 jul. 2020.

IBGE. Censo demográfico: 1980. IBGE, Rio de Janeiro, 2021c.

Disponível em: https://biblioteca.ibge.gov.br/index.php/

bibliotecacatalogo?view $=$ detalhes\&id=772. Acesso em: 20 jul. 2020.

IBGE. Censo demográfico: 1991. IBGE, Rio de Janeiro, 2021d. Disponível em: https:/ / biblioteca.ibge.gov.br/biblioteca-catalogo?id=782\&view=detalhes. Acesso em: 20 jul. 2020.

IBGE. Censo demográfico: 2000. IBGE, Rio de Janeiro, 2021e. Disponível em: https:/ / biblioteca.ibge.gov.br/biblioteca-catalogo.html?id=769\&view=detalhes. Acesso em: 20 jul. 2020.

IMESC. PDDI da Grande São Luís. São Luís: IMESC, 2017.

IPEA. Índice de Vulnerabilidade Social: 2010 a 2018. IPEA, Rio de Janeiro, 2018. Disponível em http://ivs.ipea.gov.br/index.php/pt/. Acesso em: 10 ago. 2020 .

KAYSER, B. L'espace non-metropolisé du territoire français. Revue

Géographique des Peyrénées et du Sud-Ouest, Toulouse, n. 2, p. 371-378, 1969.

LEFEBVRE, H. O direito à cidade. São Paulo: Centauro, 2011.

LENCIONI, S. Metropolização do espaço: processos e dinâmicas. In: FERREIRA, Á.; RUA, J.; MARAFON, G. J.; SILVA, A. C. P. (org.).

Metropolização do espaço: gestão territorial e relações urbano-rurais. Rio de Janeiro: Consequência, 2013. p. 17-34.

LENCIONI, S. Metrópole, metropolização e regionalização. Rio de Janeiro: Consequência, 2017.

MARANHÃO. Lei Complementar no 038, de 12 de janeiro de 1998. Da instituição da Região Metropolitana da Grande São Luís. Diário Oficial, São Luís, p. 1-22, jan. 1998.

MARANHÃO. Lei Complementar no 069, de 23 de dezembro de 2003. Da instituição da Região Metropolitana da Grande São Luís. Diário Oficial, São Luís, p. 3, 24 dez. 2003. 
MARANHÃO. Lei Complementar no 161, de 03 de dezembro de 2013. Da instituição da Região Metropolitana da Grande São Luís. Diário Oficial, São Luís, p. 1, dez. 2013.

MARANHÃO. Lei Complementar no 174, de 25 de maio de 2015. Da instituição da Região Metropolitana da Grande São Luís. Diário Oficial, São Luís, p. 1-7, 1 junho 2015.

MOREIRA, T. S. Gestão metropolitana: a Região Metropolitana da Grande São Luís e os desafios das políticas urbanas. 2013. 137 f. Dissertação (Mestrado em Desenvolvimento Socioespacial e Regional) - Programa de Pós-Graduação em Desenvolvimento Socioespacial e Regional, Universidade Estadual do Maranhão, São Luís, 2013.

MOURA, R. A dimensão urbano-regional na metropolização contemporânea. EURE, Santiago, v. 38, n. 115, p. 5-31, set. 2012.

ONU PREVÊ que cidades abriguem 70\% da população mundial até 2050. ONU News, [s. l.], 19 fev. 2019. Brasil. Disponível em: https://news.un.org/ pt/story/2019/02/1660701. Acesso em: 6 jul. 2020.

PARÁ. Lei Complementar no 027, de 19 de outubro de 1995. Institui a Região Metropolitana de Belém e dá outras providências. Foro Nacional de Entidades Metropolitanas, São Paulo, [s. d.]. Disponível em: https:/ / fnembrasil.org/wp-content/uploads/2017/10/RM-BELEM-LEICOMPLEMENTAR-027.pdf. Acesso em: 06 jul. 2020.

PARÁ. Lei Complementar nº 072, de 20 de abril de 2010. Institui a Região Metropolitana de Belém e dá outras providências. Diário Oficial, Belém, cad. 4, p. 9, 30 abr. 2010.

PARÁ. Lei Complementar no 076, de 28 de dezembro de 2011. Institui a Região Metropolitana de Belém e dá outras providências. Diário Oficial, Belém, cad. 2, p. 8, 28 dez. 2011.

\section{PORTELA, R. S. Políticas habitacionais em cidades amazônicas:}

Belém e São Luís na perspectiva comparativa. 2011. 305 f. Tese (Doutorado em Desenvolvimento Socioambiental) - Programa de Pós-Graduação em Desenvolvimento Sustentável do Trópico Úmido, Núcleo de Altos Estudos Amazônicos, Universidade Federal do Pará, Belém, 2011.

SANTOS, M. A urbanização brasileira. São Paulo: EDUSP, 2008. 
SANTOS, T. V. Metrópole e região na Amazônia: trajetórias do planejamento e da gestão metropolitana em Belém, Manaus e São Luís. 2015. 276 f. Tese (Doutorado em Desenvolvimento Socioambiental) - Programa de Pós-Graduação em Desenvolvimento Sustentável do Trópico Úmido, Núcleo de Altos Estudos Amazônicos, Universidade Federal do Pará, Belém, 2015.

SCOT'T, A. J.; AGNEW, J.; SOJA, E.; STORPER, M. Cidades-regiões globais. Espaço e Debates, São Paulo, n. 41, p. 11-25, 2001.

SECID; IMESC. Plano Diretor de Desenvolvimento Integrado (PDDI) da Região Metropolitana da Grande São Luís. São Luís: Governo do Estado do Maranhão, 2018.

SEDOP. Estudo de delimitação da região metropolitana de Belém. Organizado por Helena Lúcia Zagury Tourinho, Andréa de Cássia Lopes Pinheiro e Leonardo Augusto Lobato Bello. Belém: SEDOP, 2018.

SOJA, E. O desenvolvimento metropolitano pós-moderno nos EUA: virando Los Angeles pelo avesso. In: SANTOS, M.; SOUZA, M. A. A.; SILVEIRA, M. L. (org.). Território: globalização e fragmentação. São Paulo: Hucitec, 1996. p. 154-168.

TRINDADE JÚNIOR, S-C. C. A cidade dispersa: os novos espaços de assentamentos em Belém e a reestruturação metropolitana. 1997. 394 f. Tese (Doutorado em Geografia Humana) - Faculdade de Filosofia, Letras e Ciências Humanas, Universidade de São Paulo, São Paulo, 1998.

TRINDADE JÚNIOR, S-C. C. Confinamento, dispersão e difusão: processos e configurações espaciais de uma metrópole em formação. In: TRINDADE JÚNIOR, S-C. C; SANTOS, T. V. (org.). O urbano e o metropolitano em Belém: (re)configurações socioespaciais e estratégias de planejamento e gestão. Rio de Janeiro: Consequência, 2019. p. 143-160.

VASCONCELOS P. JR., M. Construção e transformação do centro urbano de São Luís-MA: uma análise do património histórico. 2015. 374 f. Tesis Doctoral (Doctorado en Geografía, Planificación Territorial y Gestión Ambiental) - Facultad de Geografía e Historia, Universitat de Barcelona, Barcelona, 2015. 